\title{
Construindo nós: paralelos e lições entre HIV/aids e covid-19 a partir da análise de redes semânticas no Twitter
}

\author{
Building knots: parallels and lessons between HIV/aids and covid-19 from \\ the analysis of semantic networks on Twitter
}

\section{Construyendo nudos: paralelismos y lecciones entre el VIH/sida y covid-19 del análisis de redes semánticas en Twitter}

\author{
Raquel Marques Carriço Ferreira ${ }^{1, a}$ \\ raquelcarrico@gmail.com | https://orcid.org/0000-0002-7307-5527
}

Gabriel dos Santos Cordeiro ${ }^{1, b}$

cordeirogbriel@gmail.com | https://orcid.org/o000-0001-7216-0167

\author{
${ }^{1}$ Universidade Federal de Sergipe, Programa de Pós-graduação em Comunicação. São Cristóvão, SE, Brasil. \\ a Doutorado em Cultura Contemporânea e Novas Tecnologias pela Universidade Nova de Lisboa. \\ ${ }^{\text {b }}$ Graduação em Comunicação Social pela Universidade Federal de Sergipe.
}

\section{RESUMO}

O presente artigo busca analisar postagens na rede social digital Twitter que contêm os termos 'HIV/aids' e ‘covid-19' publicadas em abril de 2021, quando o Ministério da Saúde amplia a vacinação contra a covid-19 para pessoas com HIV/aids. Nosso objetivo foi o de comparar os dois acontecimentos epidemiológicos do país, evidenciar paralelos, subjetividades e lições a partir do corpus. Para tanto, optamos por um método quantiqualitativo de análise de redes semânticas baseada na coleta de conteúdos digitais, identificandose os pares ou o conjunto de palavras que mais se conectam, formando redes de significações análogas, denominadas clusters. Como resultado, identificamos a polarização político-partidária dos comentários sobre covid-19 e HIV/aids no Twitter, a reemergência dos estigmas associados a grupos específicos, como de homossexuais e asiáticos, o espalhamento em larga escala de desinformação sobre as duas doenças, revelando um campo de tensões e de disputas narrativas e midiáticas como ferramenta 'necropolítica'.

Palavras-chave: HIV/aids; Covid-19; Comunicação; Twitter; Análise semântica.

\section{ABSTRACT}

This article seeks to analyze posts on the digital social network Twitter containing the terms 'HIV/aids' and 'covid-19' published in April 2021, when the Ministry of Health expands vaccination against covid-19 for people with HIV/aids. Our objective was to compare the two epidemiological events in the country, highlighting parallels, subjectivities and lessons from the corpus. In order to do that, we chose a quanti-qualitative method of analysis of semantic networks based on the collection of digital content, identifying 
the pairs or sets of words that most connect, forming networks of analogous meanings, called clusters. As a result, we identified the political-partisan polarization of comments on covid-19 and HIV/aids on Twitter, the re-emergence of stigmas associated with specific groups, such as homosexuals and Asians, the largescale spread of misinformation about the two diseases, revealing a field of tensions and narrative and media disputes as a 'necropolitical' tool.

Keywords: HIV/aids; Covid-19; Communication; Twitter; Semantic analysis.

\section{RESUMEN}

Este artículo busca analizar publicaciones em la red social digital Twitter que contienen los términos 'VIH/ sida' y 'covid-19' publicados en abril de 2021, cuando el Ministerio de Salud amplía la vacunación contra covid-19 para personas con VIH/sida. Nuestro objetivo fue comparar los dos eventos epidemiológicos en el país, destacando paralelos, subjetividades y lecciones del corpus. Por ello, optamos por un método cuanticualitativo de análisis de redes semánticas basado en la recolección de contenido digital, identificando los pares o conjuntos de palabras que más conectan, formando redes de significados análogos, llamados clusters. Como resultado, identificamos la polarización político-partidista de los comentarios sobre el covid-19 y el VIH/sida en Twitter, el resurgimiento de estigmas asociados con grupos específicos, como los homosexuales y los asiáticos, la difusión a gran escala de información errónea sobre las dos enfermedades, revelando un campo de tensiones y disputas narrativas y mediáticas como herramienta 'necropolítica'.

Palabras clave: VIH/sida; Covid-19; Comunicación; Twitter; Análisis semántico.

Contribuição dos autores:

Concepção e desenho do estudo: Raquel Marques Carriço Ferreira e Gabriel dos Santos Cordeiro.

Aquisição, análise ou interpretação dos dados: Gabriel dos Santos Cordeiro.

Redação do manuscrito: Gabriel dos Santos Cordeiro.

Revisão crítica do conteúdo intelectual: Raquel Marques Carriço Ferreira.

Declaração de conflito de interesses: não há.

Fontes de financiamento: não houve.

Considerações éticas: não há.

Agradecimentos/Contribuições adicionais: não há.

Histórico do artigo: submetido: 11 ago. 2021 | aceito: 05 fev. 2022 | publicado: 25 fev. 2022.

Apresentação anterior: não houve.

Licença CC BY-NC atribuição não comercial. Com essa licença é permitido acessar, baixar (download), copiar, imprimir, compartilhar, reutilizar e distribuir os artigos, desde que para uso não comercial e com a citação da fonte, conferindo os devidos créditos de autoria e menção à Reciis. Nesses casos, nenhuma permissão é necessária por parte dos autores ou dos editores. 


\section{INTRODUÇÃO}

O contexto político brasileiro nunca se mostrou tão complexo como o de agora, sobretudo após entrarmos em uma das maiores crises sanitárias, desencadeada pela covid-19 (WERNECK; CARVALHO, 2020). Em 29 de abril de 2021, alcançamos 400 mil mortes por covid-19 em pouco mais de um ano do surgimento da doença no país (BRASIL, 2022) - o primeiro caso brasileiro foi registrado em 26 de fevereiro de 2020. Em paralelo, completamos, no ano de 2021, 40 anos desde o primeiro caso do vírus HIV registrado no Brasil. A epidemia da aids no país matou 349.784 pessoas de 1980 até dezembro de 2019 (BRASIL, 2019). Dois vírus aparentemente muito diferentes, mas que, correlacionados, podem oferecer lições para pensarmos os desafios e os riscos que se descortinam.

Embora a resposta ao HIV/aids avance em passos muito mais lentos (ABIA, 2021), o Ministério da Saúde anunciou no dia 30 de março de 2021 a inclusão de pessoas que vivem com HIV/aids no grupo prioritário de vacinação contra a covid-19 (BRASIL, 2021). Tal medida é uma vitória na história da luta contra o HIV, indo na contramão do contexto brasileiro atual, afetado pelas recentes ameaças do governo, como, por exemplo, a intervenção ao programa nacional de combate à disseminação do vírus HIV $^{1}$ (G1, 2019) e as declarações preconceituosas, moralistas e cientificamente infundadas de autoridades políticas (GULLINO, 2020²; PUTTI, 20213). Enquanto o HIV foi amplamente difundido como 'câncer rosa', 'peste gay', doença de 'puta, viado [sic], estrangeiro e drogado' (SONTAG, 1989; ALMEIDA, 2017), a covid-19 tem sido classificada de 'vírus chinês', o que alimenta o preconceito e as ações de discriminação de asiáticos em vários países. Evidenciamos, portanto, a culpabilização e o estigma que se firmaram ao longo dos anos aos grupos que seriam o 'público certeiro' do HIV e hoje da covid-19. Dessa forma, o estigma encontra-se não como qualidade fixa, mas como construção sociocultural, cujo processo é histórico, mutável e se estabelece nas relações de depreciação do outro (GOFFMAN, 1988).

A circulação desse tipo de conteúdo acaba reforçando discursos preconceituosos e violentos, resultando em ações factuais contra grupos sociais específicos - neste caso, grupos étnicos asiáticos e LGBTQIA+. Consequentemente, a associação entre ambos os contextos epidemiológicos e os grupos estigmatizados, embasados na desinformação, é um dos elementos que ajuda a explicar o aumento do preconceito racial e dos crimes de ódio contra asiáticos no Brasil e em outros lugares do mundo, como Estados Unidos e Reino Unido (MOREIRA, 2020; SAYURI, 2021; REDAÇÃO, 2020a). Ademais, os episódios já conhecidos de violência contra pessoas LGBTQIA + no país só avança - foram 237 vítimas só no último ano (237 LGBT+..., 2021).

Nesse contexto, tanto antes quanto agora, os discursos e as narrativas acerca dos fatos compõem um imaginário coletivo no qual os entendimentos sobre as doenças parecem ser intencionalmente distorcidos e instauram um efeito necropolítico que está mais presente do que imaginamos (CAZEIRO; NOGUEIRA; SOUZA, 2020). Posto isso, trazemos os conceitos de necropolítica (MBEMBE, 2016) e de biopoder (FOUCAULT, 1988) para pensar os processos políticos atuais no Brasil e explicar a soberania de um Estado neoliberal contemporâneo que reconfigura profundamente as relações políticas e sociais, subjugando a vida ao poder da morte, ou seja, implementando mecanismos que operam pelo fazer morrer e pelo deixar

1 Por meio de um decreto governamental, o nome do Departamento de Vigilância, Prevenção e Controle das Infecções Sexualmente Transmissíveis, do HIV/aids e das Hepatites Virais foi alterado para Departamento de Doenças de Condições Crônicas e Infecções Sexualmente Transmissíveis, rebaixando a área de HIV/aids a uma coordenação. Dessa forma, o novo departamento agora também se ocupa de outros agravos, como hanseníase e tuberculose (G1, 2019).

2 Bolsonaro fala publicamente que pessoas que vivem com HIV/aids são uma "despesa para todos no Brasil, além de um ‘problema sério' para a própria pessoa” (GULLINO, 2020).

3 Em discurso na cidade de Chapecó (SC), o presidente Jair Bolsonaro volta a defender o uso do chamado 'tratamento precoce' contra a covid-19, que utiliza medicamentos sem eficácia comprovada e compara que nos anos 1980 também foi utilizado tratamento precoce para HIV. Ele complementa: "Por que não se combateu também? Porque o HIV era mais voltado para uma classe específica, que tinham comportamentos sexuais diferenciados" (PUTTIN, 2021). 
viver. Tais conceitos tornam-se importantes aliados para questionar e refletir sobre os direcionamentos e os sentidos atribuídos pelo governo brasileiro ao cenário atual de HIV/aids e covid-19.

Neste trabalho, analisamos as postagens feitas no Twitter com as palavras-chave "HIV OR aids OR soropositivo AND covid" durante o período de 30 março de 2021 a 30 abril de 2021 - mês em que o Brasil chegou a 400 mil mortes pela covid-19, quando as Pessoas Vivendo com HIV/aids (PVHA) foram inseridas nos grupos prioritários para vacinação e o presidente fez uma comparação entre ambas as pandemias. Nosso objetivo é refletir sobre os paralelos, as subjetividades e as lições entre a crise pandêmica atual e a resposta brasileira ao HIV/aids, evidenciando a reemergência do estigma e a difusão de desinformação, enquanto instrumentos necropolíticos.

\section{METODOLOGIA}

Ao considerar os fatos mencionados anteriormente e seus desdobramentos como terreno de investigação, as possibilidades de escolha para seleção do corpus eram múltiplas e, nesse sentido, optamos por trabalhar com as publicações de mídias sociais, com foco empírico no Twitter. A escolha justifica-se pela acessibilidade aos dados da plataforma (GIGLIETO; ROSSI; BENNATO, 2012), mas também - e talvez principalmente por entendermos que o Twitter se tornou um território virtual fértil para pesquisas sobre fenômenos sociais e de opinião pública (RECUERO, 2016).

Nessa perspectiva, as especificidades do espaço digital - como a capacidade de registro, a permanência de conteúdo e de recuperação - tornam o estudo das redes sociais na internet mais acessível, amplo e ágil que, por exemplo, o volátil diálogo face a face (RECUERO, 2014). O mapeamento desse campo pode fornecer análises precisas de grande número de dados. Entretanto, é preciso ter em mente que as plataformas exercem influência direta nas interações por elas mediadas.

Inicialmente, fizemos a coleta desses tweets através de raspagem de dados (ALVES, 2016) com o script 'snscrape', em linguagem Python, que permite a coleta das publicações sem as restrições de API (Interface de Programação de Aplicação), ou seja, interfaces entre aplicativos que determinam quais informações podem ser fornecidas) e garante que todas as publicações não deletadas serão contabilizadas. Buscamos tweets, em português, que apresentassem simultaneamente as palavras-chave "HIV/aids" e "covid-19" publicados entre os dias 30 de março de 2021 (pessoas com HIV/aids foram incluídas nos grupos prioritários para vacinação contra a covid-19) e 30 de abril de 2021 (400 mil mortes pelo coronavírus e declaração pública do presidente Bolsonaro comparando com a epidemia de HIV/Aids). Levantamos, ao todo, 1.707 comentários, que foram organizados em uma planilha e compõem o nosso corpus.

Em seguida, optamos por um método quantiqualitativo já utilizado em pesquisas anteriores no campo da comunicação social (RECUERO, 2016; REGATTIERI et al., 2014; PAZ; MEIRELLES, 2018; MALTA; COSTA; MEIRELLES, 2019). A análise de redes semânticas é uma forma alternativa da análise de conteúdo que, "no lugar de codificar diretamente as mensagens para responder à pergunta de pesquisa, [...] representa primeiramente o conteúdo das mensagens como uma rede de objetos" (ATTEVELDT, 2008, p. 4, tradução nossa). Tal método, derivado principalmente da ciência da computação, defende ser possível definir as linhas discursivas de um texto a partir da observação da relação entre os vocábulos, mais especificamente o número de coocorrências de pares de palavras (DANOWSKI, 1993).

Nesse âmbito, os dados coletados foram processados no programa WORDij (DANOWSKI, 1993), identificando os pares ou o conjunto de palavras que mais se conectam. Vocábulos cujos significados não acrescentariam à análise, como conjunções, preposições, pronomes e conjugações do verbo 'ser' foram removidos da seleção. Posteriormente, o material foi trabalhado no software Gephi (BASTIAN; HEYMANN; JACOMY, 2009) através do layout ForceAtlas2 e adaptado para mapas visuais, podendo ser observado em sua forma simplificada na Figura 1. 


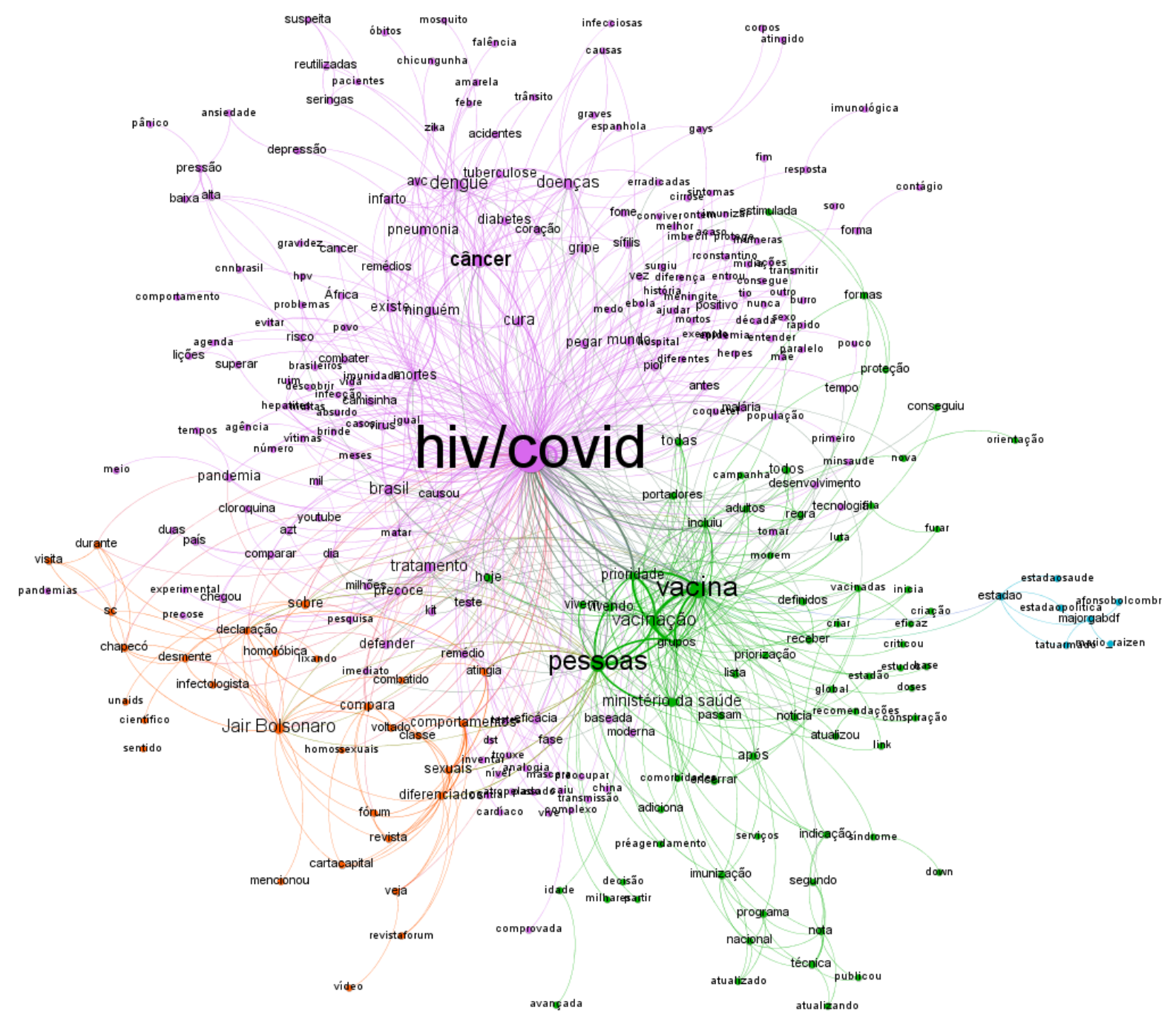

Figura 1 - Rede geral

Fonte: elaboração dos autores.

Nesse mapa, cada palavra se corresponde a um nó (círculo colorido), que varia de tamanho conforme a quantidade de pares que essa palavra estabelece. Os nós são interligados pelos laços (linhas entre os círculos), baseados nas coocorrências entre esses pares. Quanto mais próximos os nós, mais frequente a relação entre eles. Por fim, as associações mais fortes formam um cluster (representado pela cor dos nós e dos laços), isto é, agrupamentos semânticos de linha discursiva aproximada. A seguir, analisaremos empírica e teoricamente os clusters e os laços identificados.

\section{RESULTADOS E DISCUSSÕES}

As redes semânticas não permitem o entendimento preciso do objeto em análise. No entanto, são eficientes ao apontar direcionamentos investigativos pertinentes - no caso, as sobressalentes linhas discursivas presentes nas postagens (MALTA; COSTA; MEIRELLES, 2019). Desse modo, a partir do resultado das redes, foi possível a busca de tweets mais específicos para representá-las. Foram observados três clusters expressivos: "HIV/covid" (HIV, aids, soropositivo, covid, covid-19, coronavírus); "vacina" (vacinas); e "Jair Bolsonaro" (Jair, presidente, Bolsonaro). Aqui, apresentaremos uma análise interpretativa, traçando paralelos e diferenças entre ambos os cenários pandêmicos, a partir da literatura existente sobre comunicação e HIV/aids no Brasil (PARKER; AGGLETON, 2001; GOFFMAN, 1988; SONTAG, 1989), 
contrapondo também com as produções mais recentes sobre covid-19 no contexto brasileiro (RECUERO; SOARES; ZAGO, 2021; RECUERO; SOARES, 2020).

\section{NEGACIONISMO, DESINFORMAÇÃO E POLÍTICA}

O cluster 1 "HIV/covid" é o mais abrangente. Somam-se a ele os termos "doenças", "câncer", "dengue", "Brasil" com bastante destaque na rede. A evidência dessas palavras na rede acontece devido ao alto número de publicações 'negacionistas' da covid-19. Não à toa, no mês em que o país completa 400 mil mortes por covid-19 e o presidente reproduz com veemência o descaso sobre a gravidade do vírus, vários comentários surgem questionando os números divulgados pelo Ministério da Saúde e as demais fontes de imprensa nacionalmente reconhecidas.

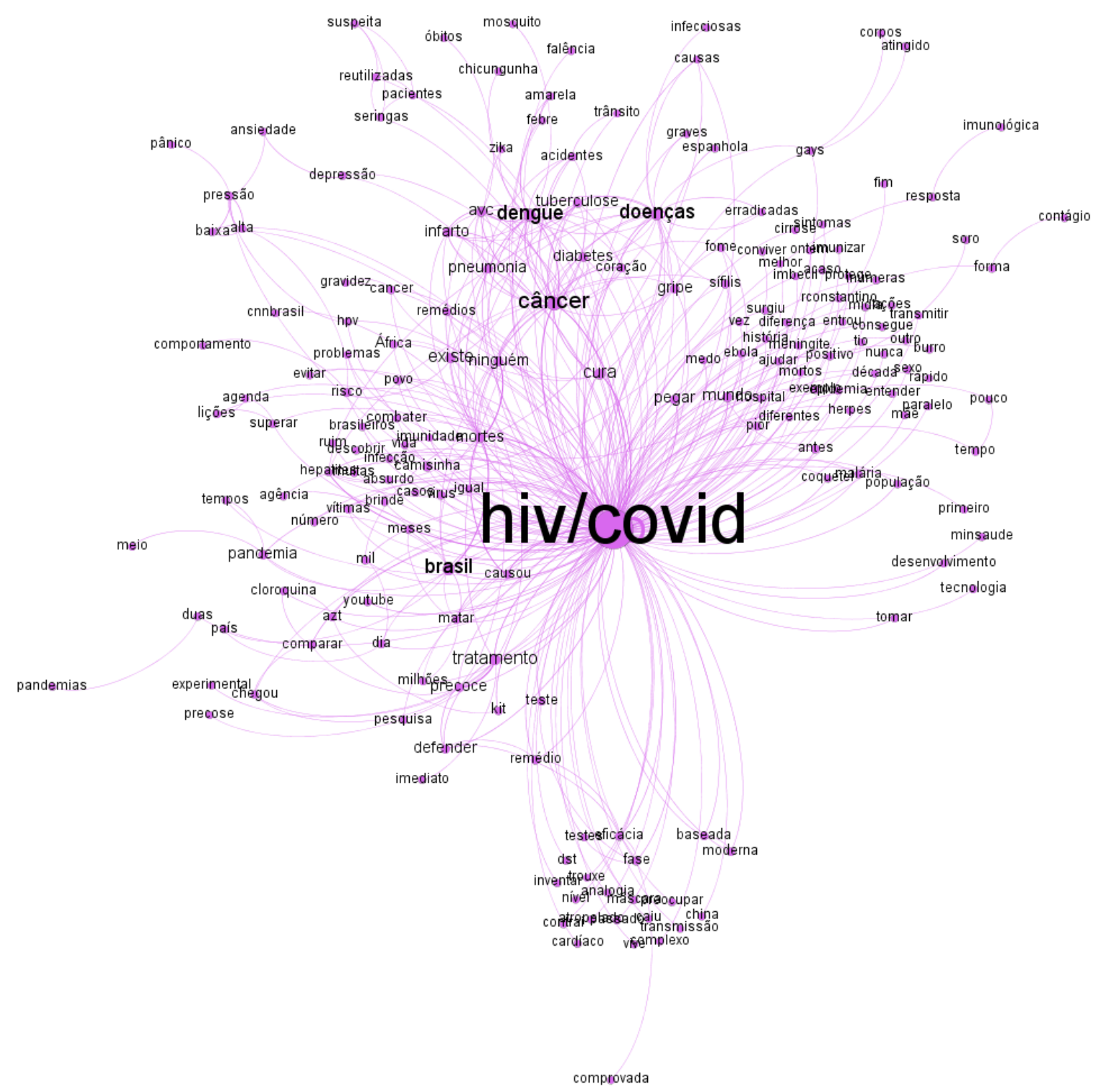

Figura 2 - Comentários negacionistas sobre a pandemia da covid-19

Fonte: elaboração dos autores. 


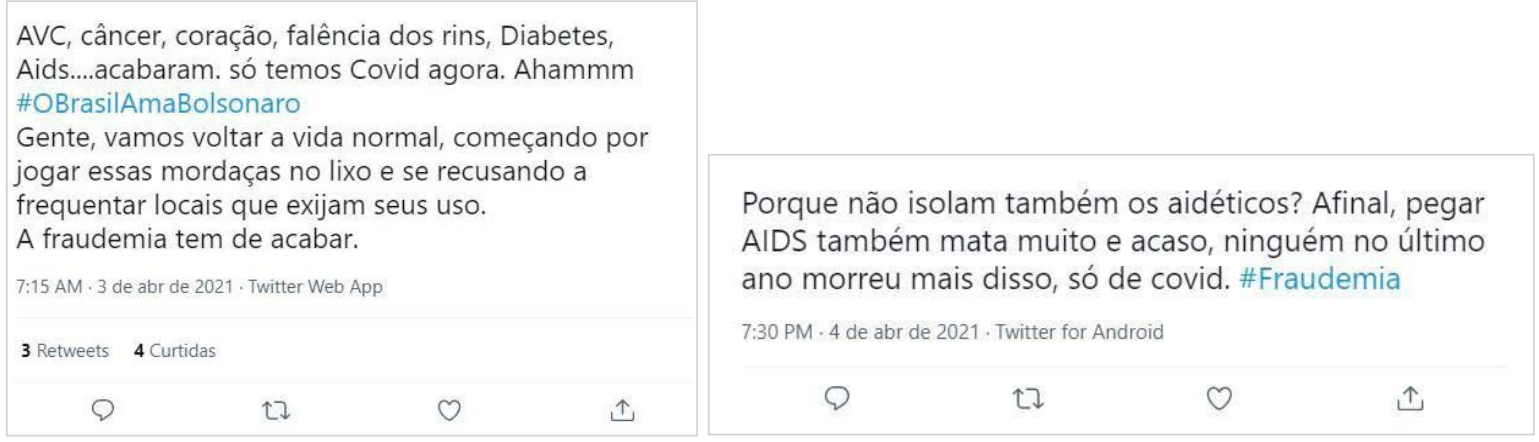

Figura 3 - Negacionismo, desinformação e política

Fonte: reprodução de postagens do Twitter feita pelos autores.

Ao analisar a rede de palavras, nos deparamos com diversas nomenclaturas de doenças e comorbidades que são causas de mortalidade em todo país, como: "dengue", "câncer", "tuberculose", "acidentes", "diabetes”, "gripe”, "pneumonia”, “AVC”, entre outras. Os termos apontam para o argumento utilizado por apoiadores da direita conservadora para refutar o número de óbitos devido a complicações relacionadas a covid-19 no Brasil, que são diariamente expostas pelo Ministério da Saúde e pela imprensa nacional, como indica o Twitter na figura 2 acima.

Essa discussão pressupõe a conceitualização de um fenômeno antigo, que já esteve presente em vários episódios da história epidemiológica humana (WHO, 2018), mas hoje é amplificado pelas redes sociais (ZAROCOSTAS, 2020) e acompanha a proliferação da covid-19 (HERNÁNDEZ, 2020). Nesse sentido, a noção de 'infodemia' pode ser compreendida como um "espalhamento generalizado de desinformação1 sobre a pandemia, principalmente, pela mídia social” (RICARD; MEDEIROS, 2020).

Partindo desse pressuposto, algumas redes sociais, como o Twitter, são veículos ainda mais favoráveis para a disseminação de informações falsas (RECUERO; SOARES; ZAGO, 2021). Além disso, de acordo com esses autores (2021), os usuários que compartilham desinformação são geralmente mais engajados e publicam mais. Consequentemente, a desinformação circula mais e em maior volume do que os outros tipos de conteúdo.

Ressaltamos ainda os desafios contemporâneos da pesquisa em redes sociais on-line, marcados pela presença dos bots (robôs responsáveis pela automatização do compartilhamento massivo de conteúdos por meio do uso da conta de usuários), que podem ou irão alterar, em alguma medida, os resultados finais da pesquisa. No corpus, percebemos uma expressiva quantidade de publicações com elementos textuais e hashtags muito semelhantes, expondo táticas contemporâneas utilizadas por grupos políticos, sobretudo da extrema direita conservadora, para impulsionar a circulação de desinformação, distorcer acontecimentos e fabricar conteúdo para favorecer a narrativa política que defendem.

$\mathrm{Na}$ linha de outras pesquisas, também foi observado um forte alinhamento da maior circulação da desinformação com elementos discursivos e ideológicos da extrema direita no Brasil, e, particularmente, dos grupos de apoio ao presidente Jair Bolsonaro (RECUERO; SOARES; ZAGO, 2021; RECUERO; SOARES, 2020). Portanto, a desinformação sobre a covid-19 é enquadrada principalmente como um assunto político-partidário (RECUERO; SOARES; ZAGO, 2021). Isso significa que as questões relacionadas ao enfrentamento da pandemia, sua gravidade e até mesmo as vacinas são entendidas como um assunto político, em que é preciso escolher 'um lado', e não compreendidas como um assunto de saúde pública, na qual todos precisam cooperar. Como consequência, as ações de controle da propagação do vírus (como o distanciamento social e o uso de máscara) e, nesse caso, dos tweets coletados, o número de óbitos 'oficiais' são lamentavelmente considerados como ideológicos, sendo até rejeitado por alguns grupos mais radicais. 
Diversas autoridades, incluindo o presidente, já fizeram uso das redes para minimizar a gravidade da doença, atacar medidas de distanciamento e pôr em dúvida a segurança das vacinas. Em 2020, a covid-19 foi comparada a um "resfriadinho" ou a uma "gripezinha" pelo atual chefe de Estado, Jair Bolsonaro, que desde o começo da pandemia de covid-19 vem minimizando seu impacto social e sanitário (REDAÇÃO, 2020b). O negacionismo também se afirmou com a sabotagem ao isolamento social e a promoção de tratamentos sem eficácia comprovada.

Sobre esse fato, Recuero, Soares e Zago (2021) ainda comentam que, quando autoridades, especialmente políticas ou da saúde, fazem declarações públicas que contêm desinformação, essa chancela não apenas impulsiona a circulação do conteúdo, como também legitima o discurso. Esse contexto apoia a postura do governo federal na falta de interesse pela aquisição de vacinas e na ausência de uma coordenação nacional para imunizar a população, além da escalada de casos e do colapso no sistema de saúde (PAULA; CAMILO; SIQUEIRA, 2021).

Podemos traçar um paralelo semelhante com o início da aids no país. De acordo com (PARKER, 2000), a doença foi amplamente direcionada por autoridades e, sobretudo, pela mídia, à parábola dos " $5 \mathrm{H}$ ": homossexuais, heroinômanos, hemofílicos, haitianos e hookers (profissionais do sexo), ou seja, o discurso negacionista que se formou encobria a doença em sujeitos 'fora do alvo' - homens e, sobretudo, mulheres heterossexuais com relacionamentos estáveis (REZENDE, 2012).

Nesse ínterim, a banalização por parte de governos reflete atrasos civilizatórios comuns a ambos os cenários. Esse tipo de postura desencadeia inúmeras consequências para o entendimento coletivo das doenças, levando ao aumento das infecções nas populações mais vulneráveis, que sofrem por falta de assistência, e até mesmo a um aumento no número de vítimas - mulheres e homens heterossexuais ${ }^{4}$, crianças e jovens (JORNAL NACIONAL, 2021) no contexto do HIV/aids e da covid-19, respectivamente. Enxergamos esse fenômeno atualmente no país, em que o presidente Bolsonaro já é popularmente chamado de 'genocida' (SOARES et al., 2021).

\section{ESTIGMA E DISCRIMINAÇÃO EM CONTEXTOS PANDÊMICOS}

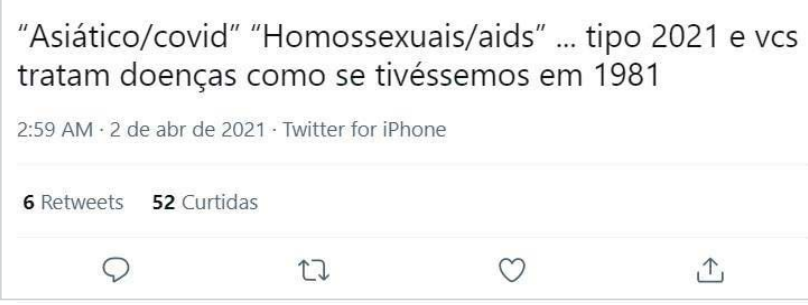

A gente é alvo deles de todas as maneiras. Seja pela doença ou pela alienação!

Nesses 40 anos de epidemia de AIDS, a população que mais morreu foram pessoas pretas, periféricas e LGBT+ .. ou seja, necropolitica.

E a história está se repetindo com o COVID.

11:46 AM $\cdot 8$ de abr de 2021 $\cdot$ Twitter for iPhone

Figura 4 - Estigma e discriminação em contextos pandêmicos

Fonte: reprodução de postagens do Twitter feita pelos autores.

É impossível falar em HIV/aids no Brasil sem pensar no estigma que acompanha essa epidemia desde os anos 1980 e, baseado nas evidências mais recentes, perceber o que se aplica à covid-19. O conceito de estigma, na verdade, é anterior ao HIV/aids. Goffman (1988) definiu o estigma no plano interpessoal e o descreveu como uma marca de desvalorização socialmente atribuída ao indivíduo. Mais à frente, Parker e Aggleton (2001) ampliaram essa ideia para o contexto do HIV/aids, discutindo o caráter social e político do

4 De acordo com o boletim epidemiológico anual, dos 41.919 novos casos de HIV registrados ano passado, 53,8\% concentramse entre homens homossexuais e bissexuais, 30,3\% entre heterossexuais e 1,3\% de Usuários de Drogas Injetáveis (UDI). Entre as mulheres, 86,8\% dos casos se inserem na categoria de exposição heterossexual, e 1,2\%, na de UDI (BRASIL, 2019). 
estigma, enquanto um "processo social e cultural que produz e reproduz a desigualdade que atravessa as nossas sociedades" (2001, p. 14). O estigma transforma, como dizem os autores, as diferenças indesejáveis em desigualdade.

Como diria Goffman (1988), o estigma depende da utilização de estereótipos que via normatização irão sustentar a ordem social e a discriminação. $\mathrm{O}$ autor ressalta ainda que existe um tipo de relação especial entre o atributo estigmatizante e o estereótipo que desvaloriza o outro num sentido intersubjetivo, interracional, referido ao 'normal' que nos socializa. Então, a pessoa estigmatizada sempre será percebida por meio do atributo indesejável, ela é reduzida a sua deficiência, a seu sofrimento físico e mental, a sua origem étnica e estrangeira, à cor de pele, a um sexismo, uma LGBTfobia e uma misoginia, e até mesmo a sua religiosidade.

Nesse âmbito, o estigma também valida poderes e hierarquias entre pessoas e legitima, por meio da produção cultural, uma violência estrutural e estruturante das "cenas das nossas vidas cotidianas" (GOFFMAN, 1988, p. 18). Considerando que essa estrutura pode ocorrer pessoalmente ou on-line (BUDHWANI; SUN, 2020), podemos observar na rede alguns pequenos agrupamentos espalhados que exemplificam essa questão do estigma. No caso do HIV/aids, palavras associadas principalmente aos corpos homossexuais - "corpos atingidos gays" - e no contexto da covid-19, aos chineses - "China".

Dessa forma, há uma tentativa de se estigmatizar a China e os chineses da mesma forma que se falava que a aids era uma doença de gays, travestis, profissionais do sexo e hemofílicos. Dois vírus que não apenas se materializam no corpo, mas cuja marca é a midiatização, as metáforas e as significações (SONTAG, 1989). Isso faz com que as pessoas, no geral, não se protejam contra as formas de contaminação, sobretudo, pelo ato sexual, como também neguem a existência da atual pandemia, acreditando em teorias conspiratórias e narrativas xenófobas.

Os estudos sobre HIV/aids atentam-se também à utilização da categoria 'grupos de risco', que voltou a ser utilizada no contexto da covid-19 e denota o estigma sobre os grupos referidos a ela. A reemergência do termo, agora relacionada aos idosos e às pessoas com problemas respiratórios, não favorece à mudança de comportamento social, mas, ao contrário, corrobora com a estigmatização, principalmente pela diferenciação social, na criação de um 'outro' não passível de 'empatia', apenas alguém a ser evitado. Nitidamente, denota-se quais vidas são precárias (BUTLER, 2015).

Voltando ao corpus, podemos perceber, a partir dos nós "mortes", "óbitos", "medo", "pânico", "depressão" etc., que tanto antes quanto agora a ideia de morte assombra nosso imaginário por conta do pânico social que ainda quizila o processo de saúde-doença por HIV ou por SARS-CoV-2. Ainda com os inúmeros avanços científicos e tecnológicos, essa sentença de morte presente no imaginário social coletivo tem relação com as infecções relacionadas a ambos os vírus, mas é importante lembrar que ainda existem certos agenciamentos políticos, subjetivos e sociais que produzem efeitos nessa perspectiva, um efeito necropolítico mais presente do que imaginamos (CAZEIRO, 2020).

Para finalizar, a análise do cluster 1 nos oferece outras palavras e conexões para pensar nas diferenças e nos paralelos entre os dois contextos epidemiológicos. Constatamos a importância da testagem e do acompanhamento do número de casos para o enfrentamento dos vírus - "testes". Emergem, então, as diferenças que estão associadas na rede às tecnologias de prevenção e ao tratamento como resposta para ambos - “camisinha”, “AZT”, "cloroquina”, "kit covid”, "precoce”, "tratamento”, "remédio”.

\section{VIVA A VIDA! VACINA E SAÚDE PÚBLICA NO BRASIL}

O cluster 2, "vacina", expõe comentários específicos, mais precisamente sobre a inclusão de pessoas que vivem com HIV/aids (PVHA) entre os grupos prioritários definidos para receber a vacina contra a covid-19. De acordo com a nova orientação, HIV/aids passa a ser considerada uma comorbidade, e pacientes que 
convivem com o vírus devem ser abarcados. As palavras com maior número de conexões são "vacinação", "pessoas", "prioridade" e "Ministério da Saúde".

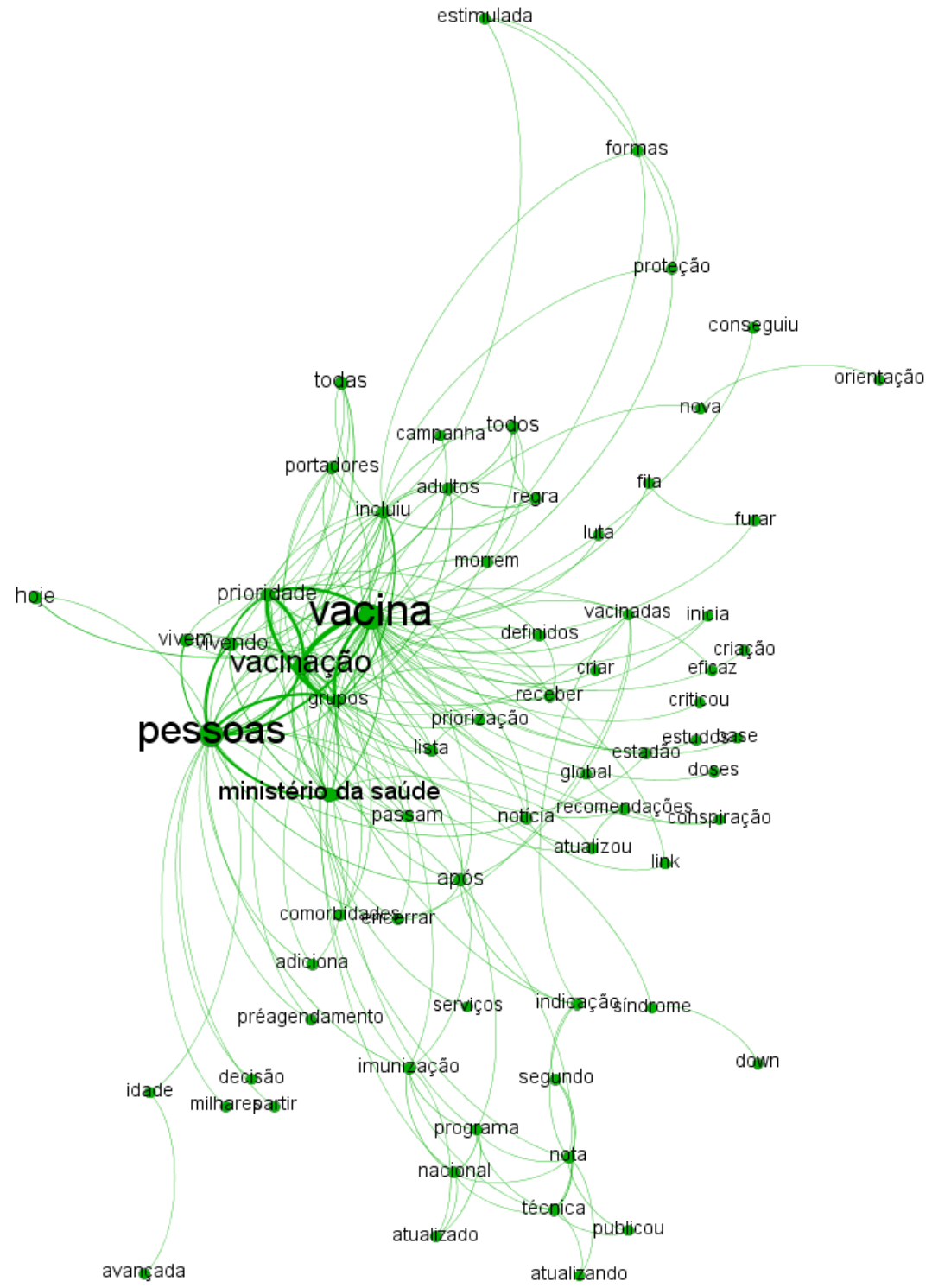

Figura 5 - Cluster "vacina"

Fonte: elaboração dos autores.

A partir de hoje todas as pessoas que convivem com HIV/AIDS serão prioridade na vacinação contra o Covid-19, por se tratarem de pessoas que se encontram em situações de vulnerabilidades sociais, além do preconceito. Essa é mais uma vitória do movimento social!

2:51 AM - 30 de mar de 2021 - Twitter for Android

$$
Q
$$

〔】

O
Se a aids é um vírus mortal é o covid tbm é um vírus mortal (pra algumas pessoas).

Pq para a aids (sem cura) tem remédios e não vacinas? Pq para o covid (tem cura) tem vacinas e não pode ter remédios?

2:36 PM - 2 de abr de 2021 - Twitter for Android
Q
饣
O
个

Figura 6 - Comentários do cluster "vacina"

Fonte: reprodução de postagens do Twitter feita pelos autores.

Apesar de não haver indícios científicos que atestem o maior risco de infecção de pessoas que vivem com HIV pelo coronavírus, a imunização desse grupo é fundamental para a prevenção de infecções oportunistas 
e para a manutenção da saúde. Portanto, essa inclusão, além de representar uma grande conquista, foi amplamente comentada em publicações no Twitter. Os nós presentes nesse cluster também abarcam cobranças sociais para uma vacina contra o HIV e um tratamento eficaz para os pacientes positivos para a covid-19. Esses são dois grandes desafios da medicina, já que a complexidade e a capacidade de sofrer mutações dos vírus dificultam os avanços.

Diferentemente da covid-19, podemos compreender, por meio de uma análise crítica, que a ideia de cura, por si só, talvez não seja a única solução para a aids. Isso ocorre porque não houve avanços culturais e sociais suficientes para a superação da exclusão social e do estigma histórico da doença. Ademais, escondese a persistência da aids em diversos países, esconde-se o sofrimento das pessoas que ainda não têm acesso ao tratamento, escondem-se as expressivas taxas de mortalidade - mesmo em países com acesso universal aos medicamentos de controle, como o Brasil - e esconde-se a falta de acesso à prevenção. Dessa forma, o imaginário social do HIV ainda é povoado por uma 'censura discursiva' que impõe barreiras à superação do problema.

\section{O GOVERNO JAIR BOLSONARO: UMA TRAGÉDIA ANUNCIADA}

Por fim, o cluster 3, o último, refere-se a comentários a respeito da declaração do presidente Bolsonaro, que comparou a covid-19 com a aids e disse que o HIV era associado a "comportamentos sexuais diferenciados". As palavras com mais coocorrências são: “Jair Bolsonaro", "comportamentos”, "sexuais”, “diferenciados”.

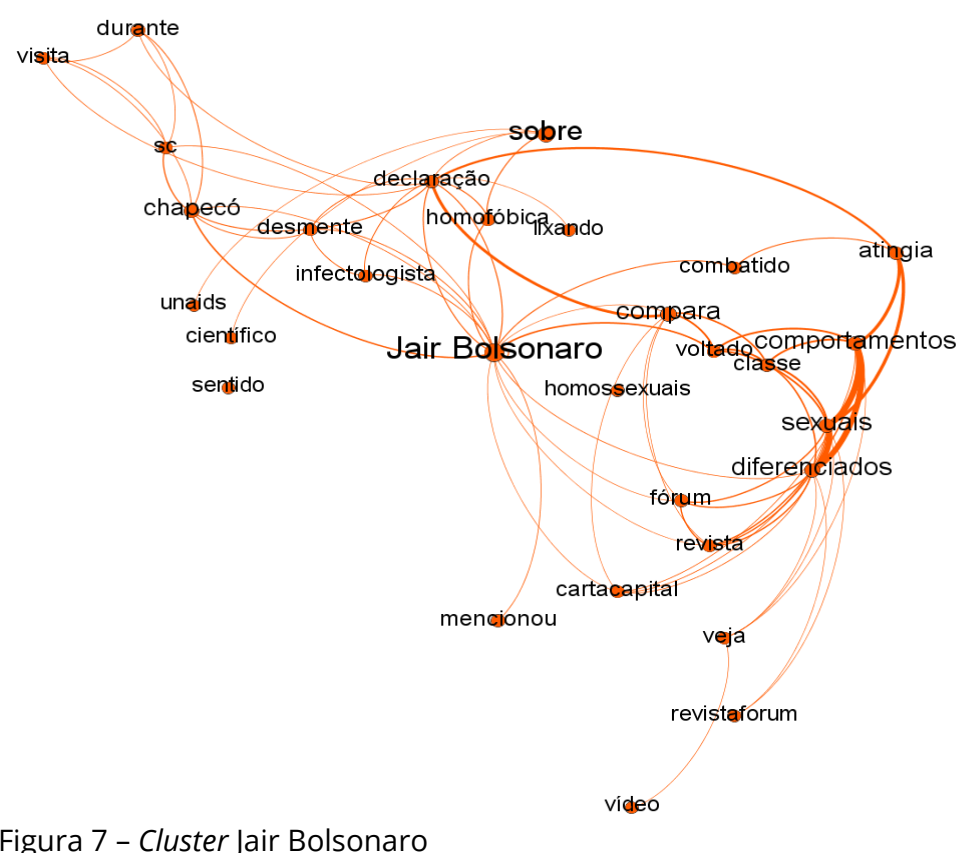

Fonte: elaboração dos autores.

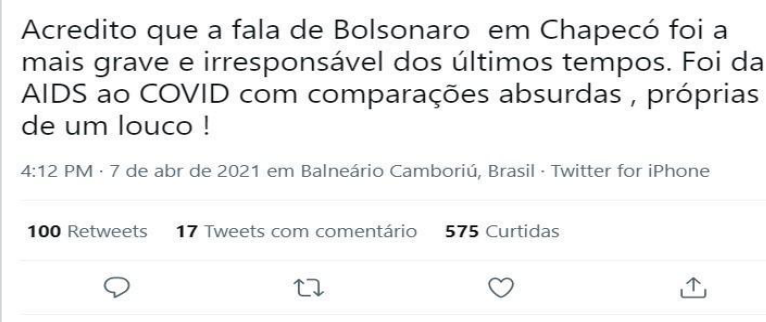

Figura 8 - Comentários do cluster Jair Bolsonaro

Fonte: reprodução de postagens do Twitter feita pelos autores.
O covid é a nova "aids". Só q pega mais fácil. E por mais q tentassem culpar um grupo, não deu tempo. Virus em gente é virus. Ao menos um mal veio abrir portas $\mathrm{p}$ o bem comum. O problema é o PR (pequi roído) \#BolsonaroGenocida q não contribui $p$ a saúde é q não tem alma.

9:57 PM · 5 de abr de 2021 - Twitter for Android 
Atualmente, o presidente Bolsonaro e o bolsonarismo legitimam a estigmatização e a discriminação das PVHA (Pessoas Vivendo com HIV/aids). Essa postura é evidente quando recordamos algumas das falas antigas do presidente sugerindo que o Estado não deveria arcar com os custos de tratamentos para pessoas que adoeceram por "uso de drogas e vadiagem", "uma despesa para todos no Brasil”, diz (GULLINO, 2020). Ademais, proteções existentes em governos anteriores, como a presença de questões LGBTQ+ nas ações relacionadas a direitos humanos, foram sistematicamente retiradas das políticas do atual governo; departamentos criados para defender políticas sobre o HIV/aids também sofreram desmanches (SUDRÉ, 2020). Portanto, algumas dessas medidas e posturas adotadas pelo governo já davam claros sinais de alerta sobre o descompromisso com a garantia de tratamento para as PVHA (Pessoas Vivendo com HIV/aids).

Na fala em que se observam os comentários visualizados na rede, Bolsonaro declarou que:

Eu acredito na ciência, mas a ciência por vezes demora. Naquela época, o que foi usado para combater o HIV? O coquetel do AZT. Era comprovado cientificamente? Não. Se não tivesse [sido] usado, não chegaríamos no futuro ao coquetel. Por que não se combateu também? Porque o HIV era mais voltado para uma classe específica, que tinham comportamentos sexuais diferenciados. E também se contraía via injeção e compartilhamento de agulhas. $\mathrm{E}$ ninguém foi contra. E chegou-se ao bom termo no futuro. Até hoje não temos uma vacina para isso. A mesma coisa agora a questão da covid-19. Porque essa campanha contra métodos e médicos e quem fala no tratamento imediato? (PUTTI, 2021).

Sem surpresas, essa fala vem carregada pelo espectro do negacionismo (evidente na primeira frase do pronunciamento), pelos estigmas (ao associar mais uma vez o vírus a um grupo específico e ao culpabilizá-lo pela persistência da doença) e pela desinformação (ao defender o uso de medicamentos para o tratamento precoce da covid-19 sem nenhuma evidência científica que ateste a eficácia do método). Ou seja, um verdadeiro desserviço para a construção do imaginário coletivo de ambos os cenários epidemiológicos.

É uma lástima para o nosso país que o atual governante seja lembrado por ser o gestor público que mais utiliza falácias em seus pronunciamentos. No primeiro semestre de 2022, atingindo a marca de 642 mil mortes no Brasil (BRASIL, 2022), ainda havia, como até hoje há, quem recorra a estratégias comunicacionais para descredibilizar a ciência e desinformar a população.

Nesse momento, é fundamental olhar para essa discussão e perceber que, de forma muito evidente, Bolsonaro sabe como jogar com a violência. Ele escolhe dizer que "o HIV não foi combatido porque era de uma classe social muito específica" (PUTTI, 2021). Ele não fala, por exemplo, dos estudos de vacina para o HIV que estão acontecendo em cinco estados brasileiros (SOUZA, 2021). Notamos, portanto, que a resposta aos problemas de saúde pública sempre foi um esforço coordenado e sólido entre gestão, ciência e sociedade civil; entretanto, este é um exemplo que o governo atual não quer seguir.

\section{CONSIDERAÇÕES FINAIS}

Nossa trajetória teórica e empírica nos permitiu chegar a algumas considerações. As postagens de brasileiros sobre HIV/aids e covid-19 em abril de 2021 indicam que discutir, nesse caso, saúde pública no Brasil é também falar em (necro)política, estigma e circulação excessiva de (des)informação em sites e em redes sociais.

Após décadas de um programa de combate ao HIV/aids razoavelmente bem-sucedido, nós estamos em uma situação crítica de tragédia e de ameaça nunca vista no enfrentamento da epidemia (ABIA, 2021). Enquanto no passado o país foi reconhecido mundialmente pelo programa de controle ao HIV/aids por meio do Sistema Único de Saúde (SUS), atualmente é lembrado como o pior do mundo na gestão da pandemia do coronavírus, segundo estudo australiano do Lowy Institute (G1, 2021). Sem dúvidas, o peso do estigma, da negação, da desinformação e dos agenciamentos políticos conservadores na resposta social às doenças é 
uma grande barreira para avançarmos. Partindo desse pressuposto, este estudo pode estimular políticas de difusão de saberes em saúde mais adequadas para lidar com futuras pandemias.

Observamos também como os comentários de caráter político-partidários encontravam-se posicionados na rede e como isso se associa com a maior atividade na propagação de conteúdo desinformativo, em comparação com o conteúdo informativo (RECUERO; SOARES; ZAGO, 2021). As publicações negacionistas e mais conservadoras apareceram mais frequentemente no cluster 1 , um agrupamento grande e que abarca as narrativas mais centrais/genéricas. Já as publicações evidentemente contrárias ao posicionamento do presidente Bolsonaro correlacionaram-se expressivamente ao cluster 3, um agrupamento semântico menor e mais específico sobre a declaração do presidente comparando a epidemia de HIV/aids com a pandemia da covid-19.

Nessa perspectiva, percebemos uma conjuntura marcada pela reemergência do conservadorismo moral, em que publicações desse viés, em sua maioria acompanhadas de conteúdos falsos, são 'infladas' nos sites e nas redes sociais e aparecem com veemência nas discussões presentes na plataforma. Portanto, essas disputas narrativas on-line têm um importante papel no processo de enquadramento dos assuntos como políticos e acabam por reforçar os estigmas nesses espaços de conversação, inclusive, e sobretudo, quando envolvem questões de sexualidade, raça, gênero e religiosidade.

Para as duas doenças não cabe estigmatizar a origem do vírus, nem o comportamento das pessoas. A responsabilização individual ou de grupos específicos reforça o estigma. É um desserviço para todos e não atinge só quem é diretamente afetado por esse agravo. O HIV, da mesma forma que a covid, é um problema de saúde pública e, como tal, deve ser tratado com seriedade e responsabilidade, em especial, por parte das instâncias governamentais, que deveriam zelar e garantir a saúde coletiva.

Ora, a luta pela vida precisa continuar, uma vez que a construção de melhores respostas à doença é uma tarefa infindável, urgente e necessária. Certamente ainda há muito que avançar!

\section{REFERÊNCIAS}

237 LGBT+ morreram vítimas da homotransfobia no Brasil em 2020, revela relatório. Agência de Notícias da Aids, São Paulo, 14 maio 2021. Notícias. Disponível em: https://agenciaaids.com.br/noticia/relatorio-deviolencia-contra-Igbts-mostra-queda-nas-mortes-por-homofobia-em-2020/. Acesso em: 07 jul. 2021.

ALVES, Marcelo. Abordagens da coleta de dados nas mídias sociais. In: SILVA, Tarcízio; STABILE, Max. (org.). Monitoramento e pesquisa em mídias sociais: metodologias, aplicações e inovações. São Paulo: Uva Limão, 2016. p. 67- 83.

ALMEIDA, Marília. Representação social das pessoas vivendo com HIV/aids na mídia impressa. 2017. 163 f. Dissertação (Mestrado em Comunicação) - Universidade Federal de Goiás, Goiânia, 2017.

ASSOCIAÇÃO BRASILEIRA INTERDISCIPLINAR DE AIDS (ABIA). HIV/aids e covid-19 no Brasil. [S. I: s. n.], 2021. Publicado pelo canal Associação Brasileira Interdisciplinar de AIDS. 1 video (95min). Disponível em: https://www.youtube.com/watch?v=S9IrDUH9blw. Acesso em: 03 jul. 2021.

ATTEVELDT, Wouter Van. Semantic network analysis: techniques for extracting, representing, and querying media content. Charleston: Booksurge, 2008.

BASTIAN, Matthieu; HEYMANN, Sebastien; JACOMY, Mathieu. Gephi: an open source software for exploring and manipulating networks. Palo Alto: Association for the Advancement of Artificial Intelligence, 2009.

Disponível em: https://gephi.org/publications/gephi-bastian-feb09.pdf. Acesso em: 03 jul. 2021.

BRASIL. Ministério da Saúde. Secretaria de Vigilância em Saúde. Boletim Epidemiológico de HIV/aids 2019, Brasília, DF, n. especial, 2019. Disponível em: http://www.aids.gov.br/pt-br/pub/2019/boletim-epidemiologicode-hivAids-2019. Acesso em: 03 jul. 2021.

BRASIL. Ministério da Saúde. Mapa covid no Brasil. Brasília, DF: Ministério da Saúde, 2022. Disponível em: https://qsprod.saude.gov.br/extensions/COVID-19 html/COVID-19 html. Acesso em: 15 jul. 2021. 
BRASIL. Ministério da Saúde. Pessoas vivendo com HIV são incluídas no grupo prioritário para receber a vacina contra a covid-19. Departamento de Doenças de Condições Crônicas e Infecções Sexualmente Transmissíveis, Brasília, DF, 28 jan. 2021. Notícias. Disponível em: http://www.aids.gov.br/pt-br/noticias/ pessoas-vivendo-com-hiv-sao-incluidas-no-grupo-prioritario-para-receber-vacina-contra-covid. Acesso em: 03 jul. 2021.

BUDHWANI, Henna; RUOYAN, Sun. Creating covid-19 stigma by referencing the novel coronavirus as the "Chinese virus" on Twitter: quantitative analysis of social media data. Journal of Medical Internet Research, Toronto, v. 22, n. 5, p. e19301, 2020. DOI: https://doi.org/10.2196/19301. Disponível em: https://www.jmir. org/2020/5/e19301/. Acesso em: 16 fev. 2022.

BUTLER, Judith. Quadros de guerra: quando a vida é passível de luto?. 7. ed. Rio de Janeiro: Civilização Brasileira, 2015.

CAZEIRO, Felipe. Por um manifesto pela vida: histórias posit(HIV)as de gays, mulheres trans e travestis. Curitiba: Editora Appris, 2020.

CAZEIRO, Felipe; NOGUEIRA; Geórgia da Silva; SOUZA, Emilly. Necropolítica no campo do HIV: algumas reflexões a partir do estigma da aids. Ciência \& Saúde Coletiva, Rio de Janeiro, v. 26, n. 3, p. p. 5361-5370, 2020. DOI: https://doi.org/10.1590/1413-812320212611.3.00672020. Disponível em: https://www.scielo.br/jl csc/a/WgVQktqZ8VtzLxk4Vxf3wPt/?lang=pt\#. Acesso em: 15 dez. 2020.

DANOWSKI, James. Network analysis of message content. In: DERVIN, Brenda; VOIGHT, Melvin J. (org.). Progress in communication sciences. New Jersey: Ablex Publishing, 1993. v. 7, p. 198-221.

FOUCAULT, Michel. A história da sexualidade: a vontade de saber. 16. ed. Rio de Janeiro: Editora Graal, 1988. v. 1.

G1. Brasil é o pior país do mundo na gestão da epidemia de covid-19, aponta estudo australiano. G1, Rio de Janeiro, 28 jan. 2021. Mundo. Disponível em: https://g1.globo.com/mundo/noticia/2021/01/28/brasil-e-pior-paisdo-mundo-na-gestao-da-epidemia-de-covid-19-aponta-estudo-australiano.ghtml. Acesso em: 03 jul. 2021.

G1. Decreto muda estrutura da área de combate à aids no Ministério da Saúde. G1, [s. I.], 22 mai. 2019. Ciência e Saúde. Disponível em: https://g1.globo.com/ciencia-e-saude/noticia/2019/05/22/decreto-mudaestrutura-da-area-de-combate-a-aids-no-ministerio-da-saude.ghtml. Acesso em: 03 jul. 2021.

GIGLIETTO, Fabio; ROSSI, Luca; BENNATO, Davide. The open laboratory: limits and possibilities of using Facebook, Twitter, and YouTube as a research data source. Journal of Technology in Human Services, v. 30, n. 3-4, p. 145-159, 2012. DOI: https://doi.org/10.1080/15228835.2012.743797. Disponível em: https://www. tandfonline.com/doi/abs/10.1080/15228835.2012.743797. Acesso em: 15 fev. 2022.

GOFFMAN, Erving. Estigma: notas sobre a manipulação da identidade deteriorada. Rio de Janeiro: Guanabara Koogan, 1988.

GULLINO, Daniel. Pessoa com HIV "é uma despesa para todos", diz Bolsonaro. 2020. O Globo, Rio de Janeiro, 05 fev. 2020. Brasil. Disponível em: https://oglobo.globo.com/sociedade/pessoa-com-hiv-umadespesa-para-todos-diz-bolsonaro-24231125. Acesso em: 03 jul. 2021.

HERNÁNDEZ, Jonathan. Desinformación y crisis sanitaria: alcances y oportunidades para las bibliotecas. Biblioteca Universitaria, Cidade do México, v. 22-23, n. 2-1, p. 110-118, 2020. DOI: https://doi.org/10.22201/ dgb.0187750xp.0.0.991. Disponível em: https://bibliotecauniversitaria.dgb.unam.mx/rbu/article/view/991. Acesso em: 09 jun. 2021.

JORNAL NACIONAL. Internação de jovens nas UTIs brasileiras atinge recorde na pandemia. G1, Rio de Janeiro, 10 abr. 2021. Notícia. Disponível em: https://g1.globo.com/jornal-nacional/noticia/2021/04/10/ internacao-de-jovens-nas-utis-brasileira-atinge-recorde-na-pandemia.ghtml. Acesso em: 03 jul. 2021.

MALTA, Renata Barreto; COSTA, Aianne Amado Nunes; MEIRELLES, Pedro Renato Cardoso. \#Casamentoreal: uma análise sociocultural a partir de postagens no Twitter. Revista Fronteiras, v. 21, n. 3 , p. 28-40, 2019. DOI: https://doi.org/10.4013/fem.2019.213.03. Disponível em: http://revistas.unisinos.br/index. php/fronteiras/article/view/fem.2019.213.03. Acesso em: 16 fev. 2022.

MBEMBE, Achille. Necropolítica: biopoder, soberania, estado de exceção, política da morte. Arte \& Ensaios, Rio de Janeiro, n. 32, p. 123-151, 2016. Disponível em: https://revistas.ufrj.br/index.php/ae/article/view/8993. Acesso em: 15 fev. 2022. 
MOREIRA, Matheus. Em meio a surto de coronavírus, orientais no Brasil relatam preconceito e desconforto. Folha de S.Paulo, São Paulo, 03 fev. 2020. Disponível em: https://www1.folha.uol.com. br/equilibrioesaude/2020/02/em-meio-a-surto-de-coronavirus-orientais-no-brasil-relatam-preconceito-edesconforto.shtml. Acesso em: 03 jul. 2021.

PARKER, Richard. Na contramão da aids: sexualidade, intervenção, política. São Paulo: Editora 34, 2000.

PARKER, Richard; AGGLETON, Peter. Estigma, discriminação e aids. Rio de Janeiro: Associação Brasileira Interdisciplinar de Aids, 2001.

PAULA, Julia Ester; CAMILO, Lucas Perrone; SIQUEIRA, Ester Wagner. A corrida pela vacinação contra a covid-19 no Brasil: como as fake news e o descaso do governo podem influenciar na imunização?. Belo Horizonte: Centro de Estudos sobre Justiça de Transição, 2021. Disponível em: https://cit.ufmg.br/2021/02/03/ a-corrida-pela-vacinacao-contra-a-covid-19-no-brasil-como-as-fake-news-e-o-descaso-do-governo-podeminfluenciar-na-imunizacao/. Acesso em: 03 jul. 2021.

PAZ, Huri; MEIRELES, Pedro. Discursos de ódio na internet: uma análise sobre a marginalidade dos corpos negros. In: CONGRESSO BRASILEIRO DE PESQUISADORES NEGROS, 10., 12-17 out. 2018, Uberlândia. Anais [...]. Uberlândia: UFU, 2018. Disponível em: https://www.copene2018.eventos.dype.com.br/resources/ anais/8/1536763720_ARQUIVO_ARTIGO-Discursosdeodionainternet_umaanalisesobreamarginalidadedoscor posnegros.pdf. Acesso em: 16 fev. 2022.

PUTTI, Alexandre. Bolsonaro compara covid-19 com HIV: "Era voltado a uma classe com comportamentos sexuais diferenciados”. Carta Capital, São Paulo, 05 abr. 2021. Política. Disponível em: https://www. cartacapital.com.br/politica/bolsonaro-compara-COVID-19-com-hiv-era-voltado-a-uma-classe-comcomportamentos-sexuais-diferenciados/. Acesso em: 03 jul. 2021.

RECUERO, Raquel. Redes sociais na internet. 2. ed. Porto Alegre: Ed. Sulina, 2014.

RECUERO, Raquel. O Twitter como esfera pública: como foram descritos os candidatos durante os debates presidenciais do $2^{\circ}$ turno de 2014?. Revista Brasileira de Linguística Aplicada, Belo Horizonte, v. 16, n. 1, 2016, p. 157-180. DOI: https://doi.org/10.1590/1984-639820158796. Disponível em: https://www.scielo.br/j/ rbla/a/f5zQwgZkJwDXG9k4Yt6p7nf/abstract/?lang=pt. Acesso em: 16 fev. 2022.

RECUERO, Raquel; SOARES, Felipe. O discurso desinformativo sobre a cura do covid-19 no Twitter: estudo de caso. E-Compós, Brasília, DF, v. 24, p. 1-29, 2020. DOI: https://doi.org/10.30962/ec.2127. Disponível em: https://www.e-compos.org.br/e-compos/article/view/2127. Acesso em: 16 fez. 2022.

RECUERO, Raquel; SOARES, Felipe; ZAGO, Gabriela. Polarização, hiperpartidarismo e câmaras de eco: como circula a desinformação sobre covid-19 no Twitter. Revista Contracampo, Niterói, v. 40, n. 1, p. 1-16, 2021. DOI: https://doi.org/10.22409/contracampo.v40i1.45611. Disponível em: https://periodicos.uff.br/ contracampo/article/view/45611. Acesso em: 16 fev. 2022.

REDAÇÃO. Coronavírus: crime de ódio contra asiáticos aumenta $21 \%$ no Reino Unido. Veja, São Paulo, 13 maio 2020a. Mundo. Disponível em: https://veja.abril.com.br/mundo/coronavirus-crime-de-odio-contraasiaticos-aumenta-21-no-reino-unidol. Acesso em: 03 jul. 2021.

REDAÇÃO. "Gripezinha ou resfriadinho" e outras 7 frases controversas de líderes mundiais sobre o coronavírus. BBC News Brasil, [s. I.], 07 abr. 2020b. Disponível em: https://www.bbc.com/portuguese/ internacional-52205918. Acesso em: 03 jul. 2021.

REGATTIERI, Lorena Lucas et al. A forma perspectiva no Twitter: uma técnica quantiqualitativa para estudos de redes sociais. In: CONGRESSO BRASILEIRO DE CIÊNCIAS DA COMUNICAÇÃO, 37., Foz do Iguaçu. 2-5 set. 2014. Anais [...]. Foz do Iguaçu: Intercom, 2014. p. 1-15. Disponível em: http://www.intercom. org.br/papers/nacionais/2014/resumos/R9-2511-3.pdf. Acesso em: 03 jul. 2021.

REZENDE, Daniela Savaget Barbosa. Mulheres e aids: silêncio e silenciamento. 2012. 99 f. Dissertação (Mestrado em Ciências). Instituto de Comunicação e Informação Científica e Tecnológica em Saúde, Fundação Oswaldo Cruz, Rio de Janeiro, 2012. Disponível em: https://www.arca.fiocruz.br/handle/icict/5800. Acesso em: 16 fev. 2022.

RICARD, Julie; MEDEIROS, Juliano. Using misinformation as a political weapon: covid-19 and Bolsonaro in Brazil. Harvard Kennedy School Misinformation Review, Cambridge, v. 1, n. 2, p. 1-8, 2020. Disponível em: https://misinforeview.hks. harvard.edu/article/using-misinformation-as-a-political-weapon-covid-19-andbolsonaro-in-brazill. Acesso em: 16 fev. 2022. 
SAYURI, Juliana. A campanha contra discurso de ódio a asiáticos na pandemia. Nexo Jornal, São Paulo, 22 mar. 2021. Expresso. Disponível em: https://www.nexojornal.com.br/expresso/2021/03/22/A-campanha-contradiscurso-de-\%C3\%B3dio-a-asi\%C3\%A1ticos-na-pandemia. Acesso em: 03 jul. 2021.

SOARES, Felipe Bonow et al. Desinformação sobre a covid-19 no WhatsApp: a pandemia enquadrada como debate político. Ciência da Informação em Revista, Maceió, v. 8, n. 1, 2021, p. 74-94. DOI: https://doi. org/10.28998/cirev.2021v8n1e. Disponível em: https://www.seer.ufal.br/index.php/cir/article/view/11246. Acesso em: 16 fev. 2022.

SONTAG, Susan. Doença como metáfora: aids e suas metáforas. São Paulo: Companhia de Bolso, 1989.

SOUZA, Ludmilla. Vacina contra HIV será testada no Brasil. Agência Brasil, São Paulo, 05 fev. 2021. Saúde. Disponível em: https://agenciabrasil.ebc.com.br/saude/noticia/2021-02/vacina-contra-hiv-sera-testada-nobrasil. Acesso em: 03 jul. 2021.

SUDRÉ, Lu. \#EuNãoSouDespesa repudia declaração de Bolsonaro sobre pessoas com HIV. Brasil de Fato, São Paulo, 07 fev. 2020. Saúde. Disponível em: https://www.brasildefato.com.br/2020/02/07/ eunaosoudespesa-repudia-declaracao-de-bolsonaro-sobre-pessoas-com-hiv. Acesso em: 03 jul. 2021.

WARDLE, Claire; DERAKHSHAN, Hossein. Information disorder: toward an interdisciplinary framework for research and policy making. Estrasburgo: Council of Europe, 2017. Disponível em: https://rm.coe.int/ informationdisorder-toward-an-interdisciplinary-framework-for-researc/168076277c. Acesso em: 03 jul. 2021.

WERNECK, Guilherme Loureiro; CARVALHO, Marilia Sá. A pandemia de covid-19 no Brasil: crônica de uma crise sanitária anunciada. Cadernos de Saúde Pública, Rio de Janeiro, v. 36, n. 5, p. e00068820, 2020. DOI: https://doi.org/10.1590/0102-311X00068820. Disponível em: https://www.scielosp.org/article/csp/2020.v36n5/ e00068820/en/. Acesso em: 15 jan. 2022.

WORLD HEALTH ORGANIZATION (WHO). Managing epidemics: key facts about major deadly diseases. Genebra: WHO, 2018. Disponível em: https://www.who.int/emergencies/diseases/managing-epidemicsinteractive.pdf. Acesso em: 15 jul. 2021.

ZAROCOSTAS, John. How to fight an infodemic. The Lancet, Londres, v. 395, n. 10225, p. 676, 2020. DOI: https://doi.org/10.1016/S0140-6736(20)30461-X. Disponível em: https://www.thelancet.com/journals/lancet/ article/PIIS0140-6736(20)30461-X/fulltext. Acesso em: 16 fev. 2022. 